
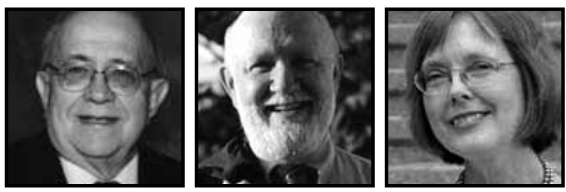

\title{
Creativity in the Person: Contemporary Perspectives
}

\author{
Donald J. Treffinger, Edwin C. Selby, and Patricia F. Schoonover \\ Center for Creative Learning
}

\begin{abstract}
All individuals, working alone or in collaboration with others, have creative characteristics, but activate and apply them in varied ways, at different times, and in response to differing tasks and conditions. A shift from asking, "How creative are you?" to the challenging question, "How are you creative?" moves us beyond looking at level of creativity ("high, average, or low") and to consider style of creativity (varied ways of expressing and applying creativity). Understanding each student's unique creative strengths enables educators to differentiate learning and instruction effectively for creativity and innovation as well as for other important educational outcomes.
\end{abstract}

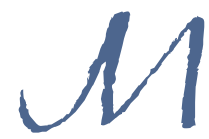

any people view creativity as a rare and elusive kind of "genius," found only in the life and work of a small number of exceptional people-renowned artists, writers, or inventors, for example, excluding both the majority of adults and (other than a few exceptional prodigies) children or youth. Theorists and researchers believed that creativity was primarily, or even exclusively, determined by internal traits or characteristics evident in those few "creatively gifted" individuals.

More recently, however, advances in theory and research have led to a new understanding, in which we view all people as demonstrating a variety of creative characteristics and preferences, varying in degree and expression. Individuals, working alone and in collaboration with others, activate and draw on those characteristics in different ways, at different times, and in response to differing tasks and conditions (Treffinger, Schoonover, \& Selby, 2013; Treffinger, Young, Selby, \& Shepardson, 2002). 
Experienced teachers certainly know students who are creative, but who differ in many other ways. Some are quiet and reflective. Others are outgoing and love interaction, sometimes to the distraction of others. Some express their creativity spontaneously in writing, art, theater, music or a combination of those. Yet others apply their imagination carefully in science and the exploration of ideas (e.g., Gardner, 1993). They may even give up other interests to pursue their passion.

Meet Lucy and Michael, two students in a twelve-member playwriting group working on an original script. The students were selected for their writing skills, interest in theater, and observed creativity; nonetheless, each approached the project and working in a group differently. Their differences were clear, for example, in their responses to one assignment. The group had been working for several weeks, first generating hundreds of ideas for a story, and then focusing, regrouping, refocusing, and finally reaching consensus on a story idea. They were assigned to take a week to develop their ideas for a completed story outline, describe who the main characters might be, and write a brief description of those characters.

At the next meeting, group members shared their plot outlines and character descriptions. When Lucy's turn came, she pulled out a large bundle of printed pages, and announced proudly that she had spent the week writing a completed script. She summarized her plot and character ideas, and noted that there was no need to do any more work. The rest of the group was taken aback by this announcement, and were concerned that Lucy's script would be adopted without consideration of any of their input. In her usual vocal way, Lucy announced that their input wasn't really needed since the script was finished, and that it made no sense to continue working and wasting time. The group could just move on to writing the music and lyrics to go with her script. Seeking to avert conflict, the teacher pointed out that not all the group members had been heard, so a decision was not yet appropriate. Somewhat reluctantly, Lucy agreed, and the reports continued. When it came time for his report, Michael pulled from his jeans a crumpled piece of paper filled with scrawled notes. He proceeded to outline a completely new story, with entirely different characters from those selected at the previous session. At once, the group exploded, with Lucy leading the charge. How could he even think of changing the story after so much work had gone into what had already been decided? Michael, replied: "Easy, this is a better idea, people will really like it."

When the teacher finally regained control of the meeting, discussion continued, with the group breaking into camps around Lucy and Michael. The teacher pointed out that some of Michael's original ideas could be worked into the story, 
while using the structure of Lucy's script would save work and help focus their ideas; the composite, with input from several others, would result in a stronger story. After some discussion the group adopted that plan, and while neither Lucy nor Michael was entirely happy, they were brought on board.

Both of these students were able to make positive contributions to the overall effort of the group. Each was beginning to explore his or her abilities as writers and as potential problem solvers. Each had demonstrated skill in writing to at least one nominating teacher, and had demonstrated real interest and commitment to the school's theater program. Yet their approaches to the assignment, and the ways they interacted with each other, were all different; each brought unique personal characteristics to the creative efforts of the group.

Because of the infinite ways creativity can be expressed, our approach to creativity focuses on understanding the complex contributions of personality, interests, and style to creative expression and productivity. Understanding each student's strengths, interests, and experiences, enables educators to differentiate learning and instruction effectively for creativity and innovation as well as for other important educational outcomes. Our approach involves a simple but powerful shift in thinking, from asking the question, "How creative are you?" to the challenging question, "How are you creative?" Such a shift challenges us to move beyond looking at level of creativity ("high, average, or low" creativity) in order to consider style of creativity (varied ways of expressing and applying creativity; e.g., Isaksen, 2004; Isaksen, Dorval, \& Treffinger, 2011; Treffinger, Selby, \& Isaksen, 2008).

\section{Reexamining Level of Creativity}

Many efforts have been made to develop and use assessment tools to sort, classify, or label people in relation to their level of creativity. Tests, checklists, and rating scales encompassing literally hundreds of characteristics abound in the literature (e.g., Davis, 2005; Plucker \& Makel, 2010; Plucker \& Renzulli, 1999; Treffinger et al., 2002). Davis (2005) catalogued more than 200 characteristics often reported as indicative of creativity, and a database on our website (www.creativelearning.com) includes annotations of more than 70 different instruments. Viewing creativity as natural and positive has enabled closer and more constructive study of the characteristics or traits associated with creativity in the person (e.g., Selby, Shaw, \& Houtz, 2005). Treffinger and colleagues (2002) reviewed more than 300 characteristics cited in the literature, 
and proposed that: "Characteristics vary within and among people and across disciplines. No one person possesses all the characteristics nor does anyone display them all the time. ... Many of these characteristics can be taught and nurtured" (p. 7.).

Considering how these characteristics might inform classroom practice, we regrouped the list into four categories, depicted in Figure 1. We concluded that creativity can result when individuals and groups generate many ideas, are able to dig deeper into those ideas, are willing and able to listen to their own inner voice, and have the motivation, openness, and courage to explore new and unusual ideas.

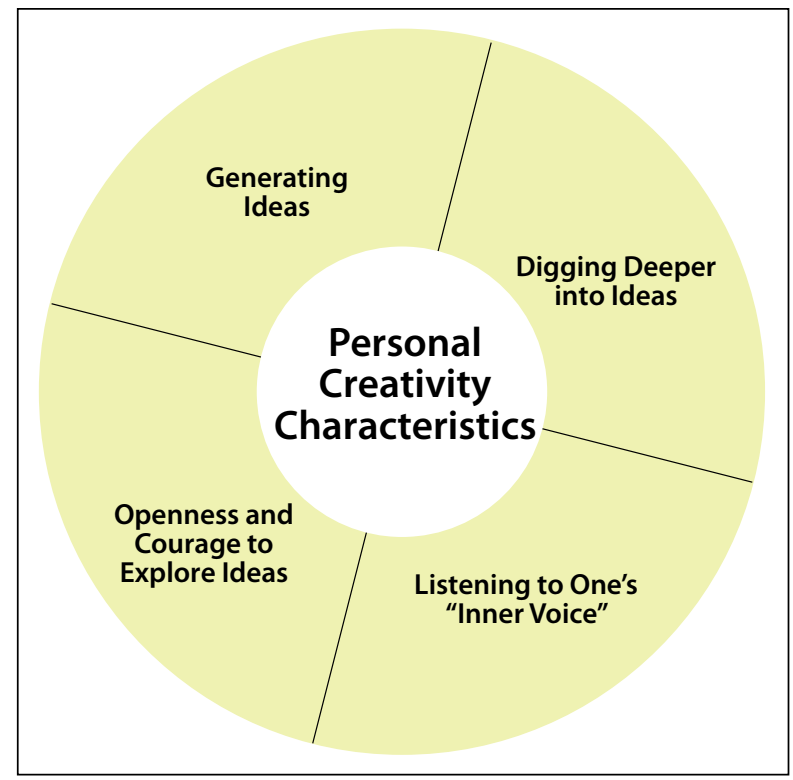

Fig. 1: Four categories of personal creativity characteristics (Treffinger et al., 2002)

The first category, Generating Ideas, includes those characteristics most often associated with divergent or creative thinking. They include characteristics associated with fluency, flexibility, originality, elaboration, and metaphorical thinking. Michael brought the group the ability to generate many original ideas; he stretched their thinking, moving away from the familiar to new and unusual possibilities, looking at the challenge in unexpected ways and from unexpected viewpoints. As the group began to look more closely at the work each of the twelve members had submitted, they chose the best ideas and combined them with the initial story idea, making the product richer, more detailed, and more interesting. 
Digging Deeper Into Ideas involves what is usually called convergent or critical thinking. Creative behaviors in this category include: analyzing, synthesizing, reorganizing, redefining, evaluating, and finding relationships. This was Lucy's strength, and as she "dug deeper," she demonstrated a desire to resolve ambiguity, make the complex simple, and to bring order from disorder.

Openness and Courage to Explore Ideas relates to problem and aesthetic sensitivity, curiosity, sense of humor, playfulness, imagination, the ability to fantasize, openness to experience, tolerance for ambiguity, risk-taking, tenacity, sensitivity, intuition, adaptability, and willingness to grow. Various members of the writing group demonstrated many of these traits. Their curiosity and sense of humor seemed endless, as was Michael's tolerance for ambiguity and risk-taking.

Finally, Listening to One's "Inner Voice" involves a person's level of motivation, self-confidence, and persistence. Again, this is a trait displayed by many of the young writers while working in the group. They believed that they were creative and showed a strong desire to create. Their self-confidence, self-efficacy, sense of purpose, and passion drove them forward. They understood their own strengths, and worked hard towards worthwhile goals. They focused on key tasks to the exclusion of most distractions, sometimes even losing sight of time, place, personal discomfort, and the social expectations of others.

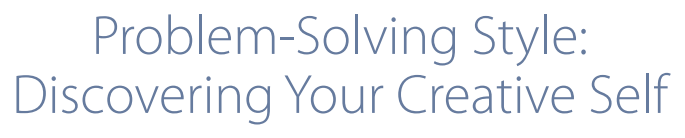

The shift in thinking toward the question, "How are you creative?" redirects our efforts to understand creativity beyond sorting, ranking, or labeling individuals based on their (presumed) level of creative ability. This approach enables us to consider unique and varied ways in which individuals express and use their creativity. It has opened new directions for research and practice that challenge us to consider style of creativity and personal preferences that promote creative productivity (Treffinger et al., 2008).

Selby, Treffinger, and Isaksen (2007a, 2007b) drew on research and theory in the areas of psychological type, cognitive style, and creativity to develop a model of problem-solving style. They described the construct of problem-solving styles as a unique set of preferences and behaviors an individual brings to situations in which 
he or she must deal with problems or manage change. They defined problem-solving styles as "consistent individual differences in the ways people prefer to plan and carry out generating and focusing activities, in order to gain clarity, produce ideas, and prepare for action" (2007a, pp. 1-2).

This model (distinct from, and more focused than generic or omnibus learning style models) involves three independent dimensions (Orientation to Change, Manner of Processing, and Ways of Deciding) that influence how individuals behave when solving problems or managing change. Each dimension involves two styles that describe differences in the ways people define problems, gather and select data, generate ideas, focus their thinking, and select and implement solutions (Treffinger, Selby, Isaksen, \& Crumel, 2007). Each style emphasizes strengths that may contribute to effective problem solving, and identifies potential limitations or "blind spots" that may hinder effectiveness.

The Orientation to Change dimension is a continuum anchored by two styles: the Explorer and the Developer. Explorers seek novelty, search widely for information regarding any task, prefer flexible structures (especially when they can design and manage those structures themselves), and prefer to keep authority at arm's length. They are often seen as unconventional and may appear to be unconcerned with rules and external regulations. Developers prefer to generate a few workable, detailed options, approach change in a gradual, efficient, or methodical manner, focus their search strategies based on relevance to the task as given, and are comfortable working within existing structures and with the guidance of authority.

The Manner of Processing dimension involves the External and Internal processing styles. Individuals who prefer the External style are engaged by social interaction. They gain energy from discussion and sharing ideas, enjoy building on the ideas of others, and are action-oriented (perhaps before giving careful consideration to those actions). On the other hand, individuals who prefer the Internal style draw their energy from reflection and weighing options carefully and thoroughly. They prefer processing tasks privately before sharing or engaging in discussion, and may become engrossed with inner events and ideas.

Ways of Deciding, the third dimension of problem-solving style, involves the Person and Task styles. Person-oriented decision makers look first at harmony and personal relations, considering the human impact of problems and challenges. They are sensitive and caring when responding to individuals about their ideas, working to avoid or ease group conflicts and considering the personal impact of decisions. 
Task-oriented decision makers look first to the quality of outcomes or results, emphasizing rigor and objective analysis. They keep people and their ideas separate, and respond to ideas not individuals. They tend to look first at what is lacking or needs improvement and may not attend to others' feelings in tense situations.

Think about the students and their writing group. Michael always sought novelty, and could be counted on to generate many original ideas, sometimes to the annoyance of others, or in disregard of decisions that had already been agreed to. The deadline for the script mattered less to him than the fun he had with his new idea. He was eager to share this idea with others, and couldn't understand why they did not see the logic of his new approach to the challenge. To Michael, structure was an annoyance to ignore when possible. When compelled to follow a set structure, he would give it the least attention possible. Lucy, on the other hand, found that structure was important in guiding her efforts. She expected that each challenge would include some structure, when that was not the case, she would develop her own structure before proceeding. Lucy was also willing to share her thoughts, and was considered the most social of the group. She had methodically and efficiently brought the whole project to a conclusion. Like Michael, she couldn't understand why others didn't see the logic of her structure and her solution to the challenge.

Theory and research on problem-solving style helps educators to recognize that creativity can be expressed and applied in many ways, or that there are many ways to be creative. The more aware individuals are of their own style characteristics, the more effective they can be in solving problems or managing change, whether working alone or in a group (e.g., Treffinger, 2007). In addition, awareness of style characteristics of students enhances educators' ability to respond effectively and in varied ways to students' needs.

\section{Implications for Practice}

Teachers or trainers who seek to nurture creativity in their students can differentiate instruction based on both the level and style characteristics of their students. Training in the tools and processes associated with the creative and analytical skills needed for creativity, innovation, and problem solving can result in increased creative productivity, both with children and adults, and for individuals and teams (Isaksen et al., 2011; Sternberg, Jarvin, \& Grigorenko, 2009; Torrance 1987, 1995; Treffinger et al., 2012). 
With students whose creative characteristics may not yet be evident, instruction can focus on building basic understanding of creative tools and processes, as well as content knowledge in areas of interest. We identify two basic sets of tools: one for generating options and another for focusing our thinking. Individuals or groups use the generating tools to produce many, varied, or unusual possibilities, to develop new and interesting combinations of possibilities, or to add richness and detail to new possibilities. Brainstorming is an example of a widely known and commonly used idea-generating tool, but there are also numerous other tools for that purpose. For focusing ideas, many people are familiar with an evaluation matrix (or "grid"), but again, there are several tools for analyzing, organizing, refining, developing, prioritizing, evaluating, or selecting options. For more information about a variety of generating and focusing tools with educational applications, see Treffinger and Nassab (2011) or Treffinger et al. (2006).

Learners whose potential is starting to emerge need opportunities to practice applying the basic tools and problem-solving methods, to build competence and confidence in their use and application. Some students need more advanced opportunities, as they are more able to express and apply their creative strengths in addressing challenges that are closer to real life. As students' creative characteristics emerge and mature, appropriate and challenging instruction extends from teaching and practicing basic tools to learning and applying a structured Creative Problem Solving (CPS) process (e.g., Isaksen et al., 2011; Treffinger, Isaksen, \& Dorval, 2006). In addition to practice problems relating directly to curriculum areas and sample "practice problems" based on realistic everyday situations and challenges, engaging applications of CPS are available in such non-profit educational programs as the Future Problem Solving Program International (FPSPI; see: www.fpspi.org).

Students who demonstrate significant strengths in all four categories of personal characteristics are likely already to be actively engaged in creative projects and building a portfolio of creative accomplishments, exhibiting the self-direction and self-regulation typical of professionals in any field. New opportunities for creative activity will be diverse and varied, but also strongly personalized for each student, and the challenge for educators, parents, or mentors may be to help find and make new connections and resources. At this level, students (working individually or as part of a highly motivated, focused team) can apply the tools and process skills they have learned to optimize their creative productivity in ways that draw on their unique personal strengths and style preferences. 
Clarity about definitions, characteristics, styles, and their implications for practice helps professionals and the public to "navigate" the breadth, depth, complexity, and elusiveness of "creativity," and to communicate more effectively. Many people have their own ideas about what makes someone or something creative, and may not often realize that they may not be in agreement even though they may be using the same words. Confusion about creativity, without the benefit of a clear, explicit understanding of its nature and characteristics, can also be challenging in the classroom dialogue between teachers and students. When a teacher tells students "to be creative," or to do an assignment "creatively," there may be no shared understanding of what "creativity" actually involves. When we better understand and value each person's style preference for creativity, and provide support for people and their products, our communication about creativity will be enhanced, and classrooms may become richer, more interesting, exciting and productive places in which to learn.

\section{Summary}

When working with students who are engaged in a complex, open-ended problem-solving project, think about the characteristics that set each student apart from others. As a result of your study of personal creativity characteristics and styles, we invite you to consider several important follow-up questions:

- What characteristics do your students display that are associated with level of creativity? What problem-solving style preferences do they display?

- How might educators, parents, or community leaders facilitate the recognition and nurture of creativity in children and youth (and, for that matter, in themselves)? What might you suggest to them that will help them recognize the strengths of each group member?

- How might individuals work together to recognize and use their diverse creative strengths to enhance or maximize their productivity?

Searching for and recognizing the personal characteristics and style preferences of students is an extensive, but engaging and worthwhile challenge. It is also not an end point, but a starting point for deliberate instruction in process tools that will lead to making the goal of "nurturing creativity and innovation" more than a matter of lip service in education. 


\section{References}

Davis, G. A. (2005). Creativity is forever (5th ed.). Dubuque, IA: Kendall-Hunt.

Gardner, H. (1993). Creating minds. New York: Basic Books.

Isaksen, S. G. (2004). The progress and potential of the creativity level-style distinction: Implications for research and practice. In: In W. Haukedal \& B. Kuvaas. (Eds.). Creativity and problem solving in the context of business management. (pp. 40-71). Bergen, Norway: Fagbokforlaget.

Isaksen, S. G., Dorval, S. G., \& Treffinger, D. J. (2011). Creative approaches to problem solving (3rd ed.). Thousand Oaks, CA: Sage Publications.

Plucker, J. A., \& Makel, M. C. (2010). Assessment of creativity. In: J. C. Kaufman \& R. J. Sternberg (Eds.). The Cambridge handbook of creativity. (pp. 48-73). New York: Cambridge University Press.

Plucker, J. A., \& Renzulli, J. S. (1999). Psychometric approaches to the study of creativity. In: R. J. Sternberg (Ed.), Handbook of creativity (pp. 35-60). New York: Cambridge University Press.

Selby, E., Shaw, E., \& Houtz, J. (2005). The creative personality. Gifted Child Quarterly, $49,4,300-314$.

Selby, E. Treffinger, D., \& Isaksen, S. (2007a). Technical manual - VIEW: An assessment of problem solving style (2nd ed.). Sarasota, FL: Center for Creative Learning, Inc.

Selby, E. Treffinger, D., \& Isaksen, S. (2007b). Facilitator guide - VIEW: An assessment of problem solving style (2nd ed.). Sarasota, FL: Center for Creative Learning, Inc.

Sternberg, R. J., Jarvin, L., \& Grigorenko, E. L. (2009). Teaching for wisdom, intelligence, creativity and success. Thousand Oaks, CA: Corwin.
Torrance, E. P. (1987). Teaching for creativity. In S. G. Isaksen (Ed.), Frontiers of creativity research: Beyond the basics (pp. 189-215). Buffalo, NY: Bearly Limited.

Torrance, E. P. (1995). Why fly? A philosophy of creativity. Norwood, NJ: Ablex.

Treffinger, D. J. (2007). Impact of style awareness on team performance. Melbourne, FL: Future Problem Solving Program International.

Treffinger, D. J., Isaksen, S. G., \& Dorval, K. B. (2006). Creative problem solving: An introduction (4th ed.). Waco, TX: Prufrock Press.

Treffinger, D. J., \& Nassab, C. A. (2011). Facilitator's guide: Generating and focusing tools. (Combined set). Sarasota, FL: Center for Creative Learning. [available as PDF from www.creativelearning.com].

Treffinger, D. J., Nassab, C. A., Schoonover, P. F., Selby, E. C., Shepardson, C. A., Wittig, C. V. et al. (2006). The CPS Kit. Waco, TX: Prufrock Press.

Treffinger, D. J., Schoonover, P. F., \& Selby, E. C. (2013). Educating for creativity and innovation. Waco, TX: Prufrock Press.

Treffinger, D., Selby, E., \& Isaksen, S. (2008). Understanding individual problem-solving style: A key to learning and applying creative problem solving. Learning and Individual Differences, 18, 390-401.

Treffinger, D., Selby, E., Isaksen, S., \& Crumel, J. (2007). An introduction to problem-solving style. Sarasota, FL: Center for Creative learning, Inc.

Treffinger, D., Young, G., Selby, E., \& Shepardson C. (2002). Assessing Creativity: A guide for educators. Storrs, CT: The National Research Center on the Gifted and Talented. 


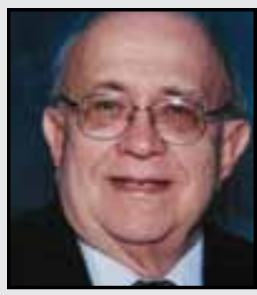

Donald J. Treffinger is the President of the Center for Creative Learning, Inc., in Sarasota, Florida. He holds the Ph.D. in Educational Psychology from Cornell University. In June 2009 Dr. Treffinger received an honorary Doctor of Laws degree from the University of Winnipeg. He has authored or coauthored more than 60 books and monographs, including Creative Problem Solving: An Introduction and Creative Approaches to Problem Solving, and more than 350 articles. Dr. Treffinger served as a member of the faculty of Purdue University, the University of Kansas, and Buffalo State College.

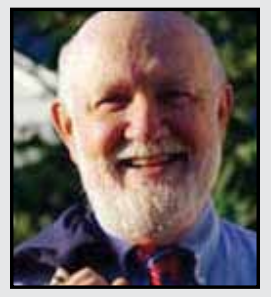

Edwin C. Selby is an Adjunct Professor of Education at New York's Fordham University and an Associate with the Center for Creative Learning in Sarasota, Florida, and was formerly a music and drama teacher. Dr. Selby is the principal author of VIEW: An assessment of problem solving style and has published articles on style and on Creative Problem Solving. He lectures and offers seminars and workshops, helping individuals and groups become more effective at solving problems. Currently, Dr. Selby is the President of the Sussex County Charter School for Technology Board of Trustees, in Sparta, New Jersey.

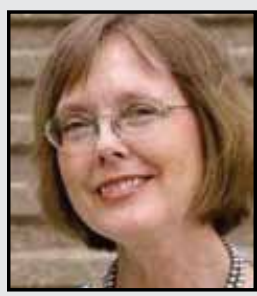

Patricia F. Schoonover teaches in the School of Education, University of Wisconsin at Stevens Point, and is an Associate of the Center for Creative Learning in Sarasota, Florida. She teaches undergraduate and graduate courses on CPS, works in the field with educators, and serves as a consultant for schools and other organizations. Dr. Schoonover's research, writing, and training interests focus on creativity, CPS, creativity style preferences, and leadership; she has published articles on creativity and style, authored a number of instructional resources on standards and thinking skills, and co-authored the CPS Kit.

\section{LINKTO:}

http://www.creativelearning.com

http://www.viewstyle.net 